\title{
PROBLEMS FOR THE ANAESTHETIST IN THE CARE OF THE OBESE PATIENT
}

\author{
J. W. R. MCINTYRE, F.F.A.R.C.S."
}

THE PURPOSE OF THIS PRESENTATION is to review the available information regarding obesity and anaesthesia, to give an account of experience with obese patients, and to draw some conclusions regarding the anaesthetic care of this type of individual. The factors that may be involved in the problem facing the anaesthetist are as follows: $(a)$ aetiology, $(b)$ associated medications, $(c)$ nutritional or electrolyte changes, $(d)$ physiological changes, $(e)$ anatomical changes, and (f) concomitant disease.

The aetiology of obesity has been reviewed by McCracken; ${ }^{1}$ of the various factors considered, it appears unlikely that many are of significance as far as anaesthesia is concerned. The ordinary obese patient shows no evidence of thyroid or pituitary abnormality, and though conditions such as myxoedema, Cushing's syndrome, Froehlich's syndrome, and insulin producing tumours of the pancreas can all produce a degree of obesity, the associated endocrine disturbances are usually primarily apparent. However, surgery in the obese patient can be associated with unanticipated complications due to hypothyroidism, hypokalemia, or adrenal insufficiency. Another rare syndrome exists in which among other signs obesity is associated with hypotonia, electromyographic studies showing no abnormality. ${ }^{2}$

Whatever the aetiology of the condition may be, diet and exercise are important factors in the treatment, ${ }^{3,4}$ as well as psychotherapy and perhaps surgery. Drugs are often used for their direct effect, or to treat related conditions such as hypertension. At a time when current thinking is much concerned with the interaction of drugs, the effects of thyroid preparations, sedative and tranquillizing drugs, and amphetamines are relevant to the anaesthetic situation. Cessation of administration of the latter may even be associated with withdrawal symptoms in the postoperative period. ${ }^{5}$ Drugs with a high lipid solubility will form reservoirs in the body of the obese patient during anaesthesia, and even when consciouness and pain responses have returned their effect may modify the action of tranquillizing, anti-emetic, or analgesic drugs given at that time. However, a realization of the potential problems mentioned so far is of little help in dealing with the principal hazards, which are cardiopulmonary in nature. They consist of a decrease in functional residual capacity, the magnitude being a function of the severity of obesity and integrity of the muscles of the thorax and diaphragm. This is exaggerated in the supine and head-down positions. Any initial hypoxia is due to uneven pulmonary perfusion ventilation ratios, and hypercapnia ensues if there is increased ventilatory impairment. The work of breathing is increased

-Department of Anaesthesia, University of Alberta Hospital, Edmonton, Alberta. 
in uncomplicated obesity because of the increased recoil force of the thoracic cage.6,7

Pulmonary hypertension develops due to a number of factors including hypoxia, increased venous return, cephalad movement of the diaphragm, and limited pulmonary expansion. Polycythaemia occurs, and an increase in systemic blood flows which is distributed principally to the fat depots and may be sufficient to double the cardiac output at rest. This increased demand on the left ventricle, associated with an increased right ventricular work load, leads to cardiac hypertrophy and possibly myocardial failure. ${ }^{8}$ Post-mortem studies of the hearts of obese patients revealed that myocardial hypertrophy is a more specific and significant alteration than reported findings of epicardial fat and fatty infiltration. ${ }^{9}$

Liver function studies have been performed in a number of obese patients, and although in a recently reported study only one out of five patients had even minor abnormalities of liver function, previous reports consistently mention the findings of impaired BSP excretion in the majority of patients, and abnormal values for thymol turbidity, cephalin flocculation, and alkaline phosphotase levels in a smaller proportion of cases. ${ }^{10}$ There is no evidence as to whether or not these patients were more susceptible to drug-induced liver damage, but liver complications are known to follow certain types of surgery in the obese, ${ }^{11}$ and some anaesthetic drugs remain in the body tissues for some time. Thus susceptibility to liver damage is a problem that must be considered in relation to the other problems of the condition, particularly if anaesthesia is for repetitive procedures, suture of a dehiscence, or restorative bowel surgery.

The anatomical structure of the obese patient is an intimidating sight in the operating room. Though the setting up of an intravenous infusion or location of the subarachnoid space may be surprisingly simple, artificial ventilation by mask and endotracheal intubation may be surprisingly difficult, and unsuccessful attempts potentially lethal. The pressure required to inflate the lungs is associated with large leaks around the mask as well as the passage of gases into the stomach, while even the insertion of a laryngoscope into the mouth in the standard fashion can be prevented by supra- and antesternal masses of fat. The delayed emptying time and the possibility of development of an intragastric pressure great enough to produce reflux through the cardia add to the problem of artificial ventilation by mask.

Another technical problem of importance is blood pressure measurement using sphygmomanometry. Recent work by King ${ }^{12}$ has shown that the most practical index of error is a percentage of occasions in which the physician would be misled by more than $20 \mathrm{~mm}$. $\mathrm{Hg}$. Under certain circumstances the anaesthetist may wish to have a more accurate measurement of the blood pressure of a particular patient than standard sphygmomanometry apparently provides.

Now that the problems associated with anaesthesia have been outlined, some details obtained from a retrospective study in an unselected series of obese patients during the past two years may be of interest. Initially attention should be paid to the definition of obesity. A consideration of height and weight does not necessarily indicate fatness, and the unsatisfactory qualities of this simple classifcation have been discussed many times. Seltzer ${ }^{13}$ suggested an alternative method of presenting height and weight data, and referred to it as the Ponderal Index. 
Weight is a measure of volume, and this increases as the cube of the linear measurement. Thus it becomes an index of shape and excludes gross body size. Using material derived from the Build and Blood Pressure Study of the Society of Actuaries, he determined that persons with a Ponderal Index below 11.6 were predominantly obese and had a sharp and generally progressive increase in mortality rate. In Figure 1 are shown the patients' real weights and their range

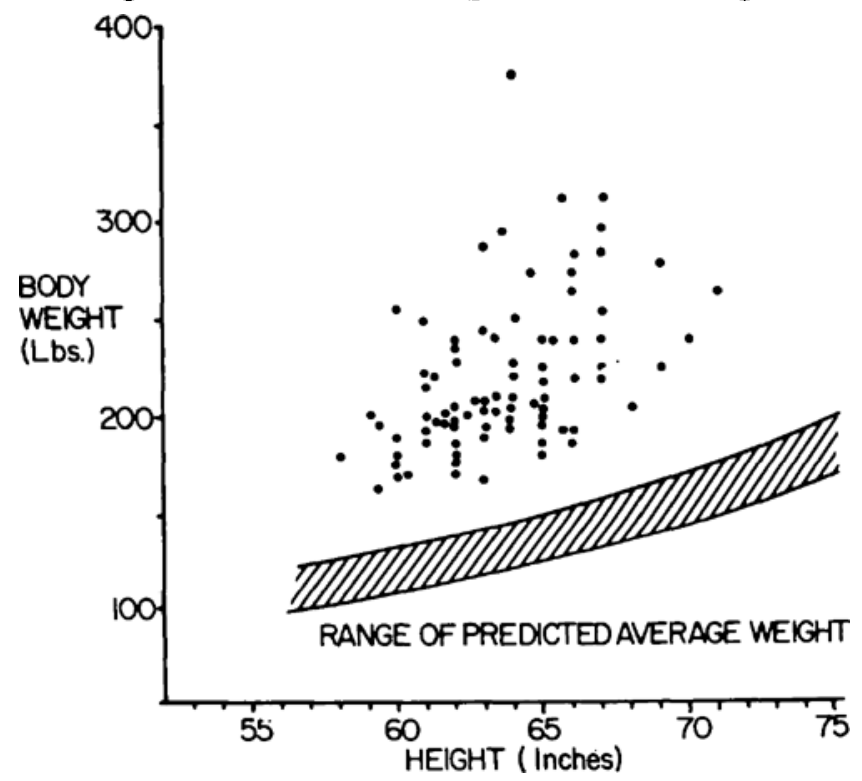

Figure 1

of normal weights. ${ }^{14}$ The Ponderal Indices of these patients lay between 8.9 and 11.5. Using an error in height measurement of one inch and an error in weight measurement of 10 per cent, it appears that eight out of a total of fifty-one patients undergoing major abdominal surgery, and six out of a total of twenty-four patients undergoing minor extra-abdominal surgery, may in fact have had indices of 11.6 or more. Two other patients had major extra-abdominal surgery. The patients were of both sexes and ranged in age between twenty and seventy-eight years, more than one-third being over fifty. The duration of surgery is shown in Figure 2.

Premedication consisted predominantly of opiates, atropine, or scopolamine, in doses customarily given to persons of normal adult weight. Thiopentone was employed for induction, except in those few instances when the anatomical structure indicated that intubation under topical anaesthesia would be safer. Maintenance agents were nitrous oxide or oxygen, supplemented with halothane or methoxyflurane, except in four cases when fentanyl or a combination of fentanyl and droperidol were used, and one case when spinal anaesthesia was employed. Neuromuscular blocking agents were used whenever necessary, and their action routinely reversed with neostigmine at the termination of surgery. No complications occurred during anaesthesia. The physical qualities of methoxyflurane, and to a lesser extent of halothane, require termination of drug administration prior to the termination of surgery. In an endeavour to obtain some idea of when 


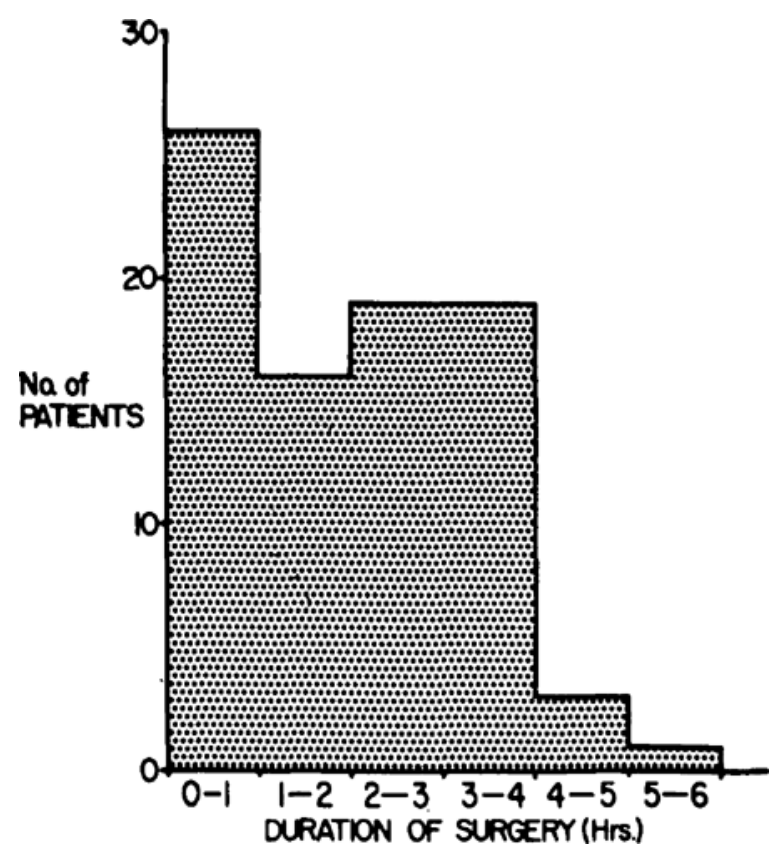

FIGURE 2

administration of methoxyflurane should cease, a randomly selected group of patients of any weight were anaesthetized using the uniform thiopentone-oxygenmethoxyflurane technique, and an attempt made to relate the duration of administration of methoxyflurane and the time after administration had ceased before the patient showed a motor response during surgery. The findings appear in Figure 3. Considering the number of variable factors involved, it is not surprising

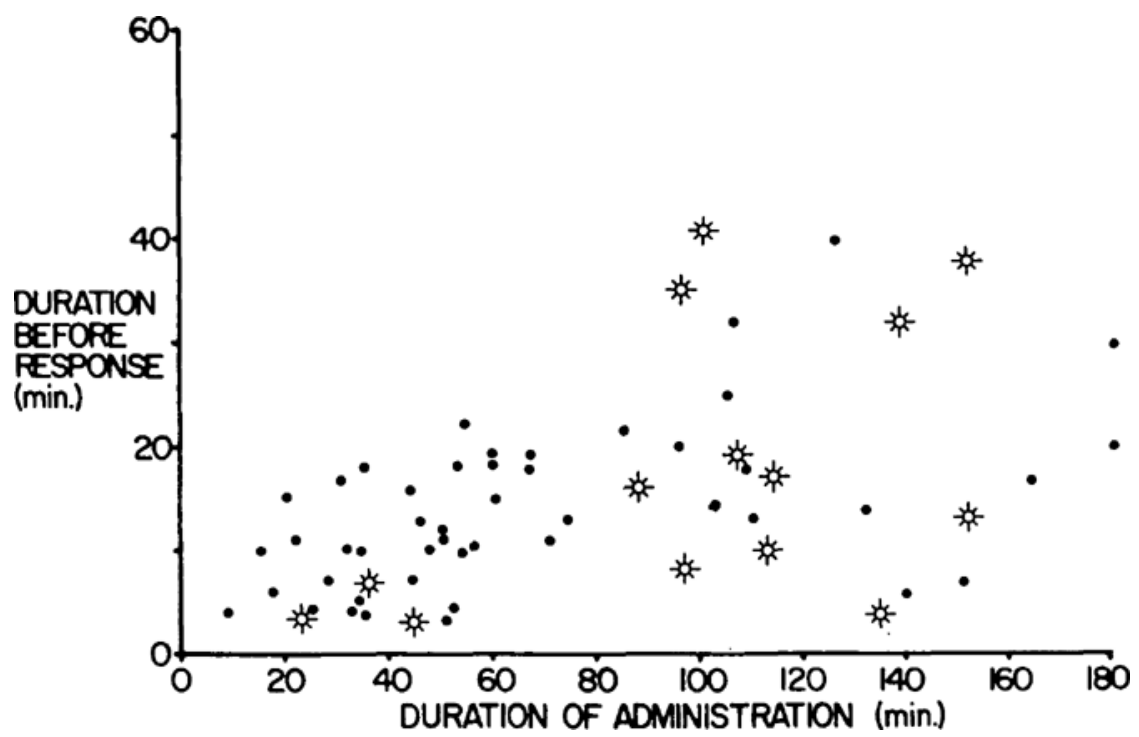

FIGURE 3. Relationship between duration of methoxyflurane administration and motor response to surgical stimulus. Dots represent normal patients, stars obese patients. 
that duration of administration was found to be an unreliable indication of when administration of methoxyflurane should be terminated, though as Wyant has pointed out, ${ }^{15}$ fatty deposits in the obese can speed awakening.

The time spent in the recovery room before the patients knew their names is shown in Figure 4 with reference to the anaesthetic technique used. Knowledge

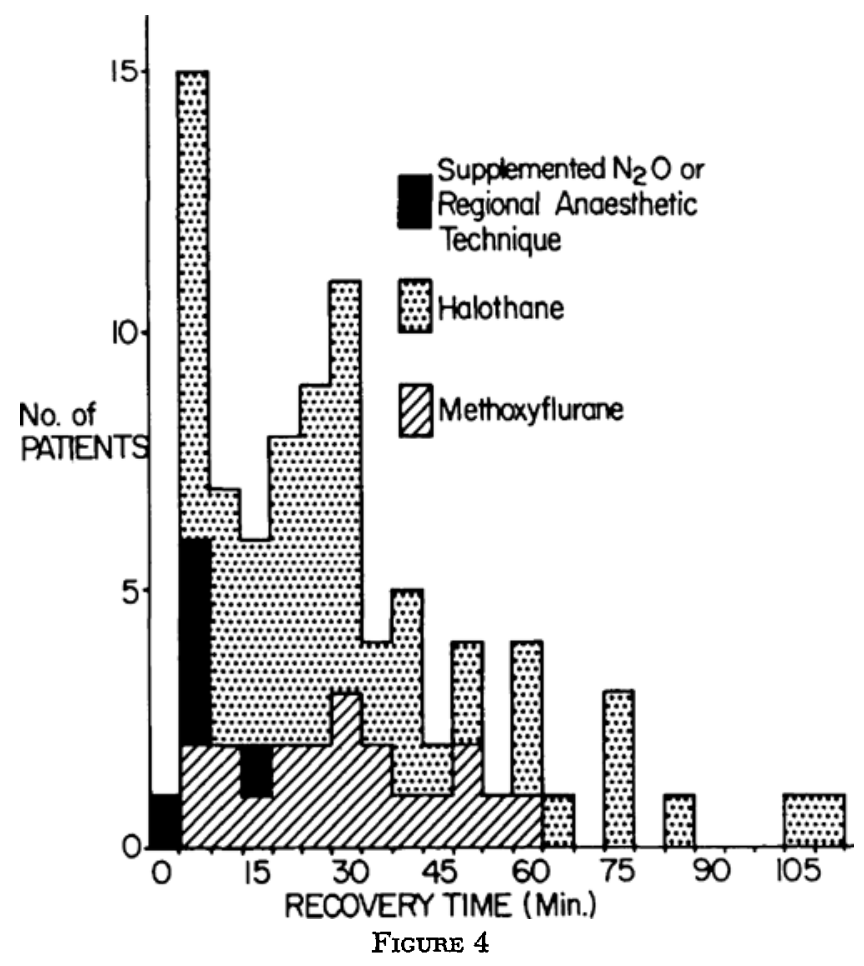

of personal identity is an early sign of being awake and the patients at this time could not necessarily actively participate in their own care.

In the past, attention has been drawn to the anaesthetic problems of obesity. ${ }^{10-20}$ The anaesthetic techniques advocated include general anaesthesia with nitrous oxide supplemented with analgesics, ${ }^{16}$ spinal, ${ }^{16-18,21}$ continuous spinal, ${ }_{1}^{19,22}$ or epidural ${ }^{17}$ analgesia, whenever this is suitable for the proposed surgery. The respiratory effects of epidural analgesia have recently been reviewed by Bromage, ${ }^{23}$ and the conclusion drawn from the evidence presented was that the abdominal expiratory activity which occurs under light general anaesthesia does not occur if epidural analgesia is induced. This is probably due to an abolition of stretch receptor activity, and to the fact that high epidural block impairs the phrenic reflex, thus reducing responses to noxious stimulation and facilitating the initiation of artificial ventilation. This is particularly desirable because high inflationary pressures may decrease pulmonary blood flow. Thus epidural analgesia at an adequate level will protect the patient from at least some of the ventilatory complications that can occur during anaesthesia, and will render unnecessary the care required in the administration of relaxant drugs. Spinal anaesthesia also has merit in this regard, but like other methods of anaesthesia it is not without hazard. ${ }^{10}$ 
It should not be forgotten that whether due to sedative drugs, posture, duration of surgery, or the block itself, ventilatory support during the operative procedure is likely to be required, and cardiovascular function may also require supportive measures, or restlessness may need treatment. Thus the same preparations for cardiopulmonary care must be made whether epidural, spinal, or general anaesthesia is used.

The general anaesthesia employed for the cases reported here was not associated during the operative period or sojourn in the recovery room with events that indicated it to be unsatisfactory. Preoperative sedation was adequate, with low doses of drug relative to body weight, although the possibility that under these circumstances the drug effects were supplemented by carbon dioxide narcosis cannot be excluded. Induction was uncomplicated and usually accomplished with thiopentone 300 to $400 \mathrm{mg}$, while excessive dosage of neuromuscular blocking drugs was avoided by monitoring with nerve stimulators where necessary. This is of course a superficial view of events during surgery, and preparations for a difficult convalescence may occur at this time. The relationship between such pulmonary complications, as occurred in this series, and events during surgical anaesthesia is unknown. One criticism of general anaesthesia is the delayed recovery of consciousness, but this is not an inevitable concomitant of general anaesthesia. The use of inhalational techniques supplemented with intravenous analgesics is usually associated with rapid recovery of mental acuity. An important requirement of any technique is the ability immediately following surgery and for several days thereafter to participate fully in cardiopulmonary care, and skilled and enthusiastic persons are needed who can supply this care. Until the perfect intramuscular analgesic is discovered, continuous epidural analgesia offers great advantages, but to achieve optimum success with this type of patient suitable psychological support is also necessary. It is a subject for conjecture whether, utilizing the same time and energy of nursing and medical supervision, operative and postoperative epidural analgesia would have achieved better results than general anaesthesia and postoperative intramuscular analgesics. In the series reported here, two out of forty-eight abdominal patients developed minor degrees of atelectasis. Other more transient chest complications occurred in some abdominal and major extra-abdominal procedures, but did not appear to prolong the convalescent period.

\section{ConClusion ANd SUMmaRY}

On the basis of the literature available and observations of seventy-seven obese patients, it is concluded that the keynotes to survival of the obese patient during surgery, whether a minor or major procedure is anticipated, are as follows:

(1) Ensurance of an unobstructed airway, by intubation awake if necessary.

(2) Use of minimal intrathoracic pressures concomitant with effective ventilation or adequate spontaneous ventilation.

(3) Positioning of the patient in a manner most suitable for ventilation and surgery.

(4) Adequate monitoring of as many parameters as the situation demands. 
(5) Ensurance of adequate means of administering drugs and fluids at the rate and in the quantity that could conceivably become necessary.

During the recovery period and convalescence, adequate pain relief and antinauseants may be combined with an active nursing program. It is of fundamental importance that, whatever technique is selected at this time, signs such as blood pressure changes, vocal activity, restlessness, and apparent sedation are each interpreted in the light of as many other details as possible, before what initially appears to be the appropriate course of action is taken. The vital thing during the postoperative period is accurate information at frequent intervals concerning the cardiovascular, respiratory, metabolic, and central nervous function of the patient.

\section{RÉSUMÉ}

Nous décrivons les problèmes de l'obésité pour les soins anesthésiques chez le malade chirurgical; nous posons ces problèmes selon l'étiologie de l'obésité, selon les médications du malade, selon les changements de nutrition et des électrolytes, selon les changements anatomiques et physiologiques et selon les maladies actuelles.

D'après la littérature à notre disposition et d'après les observations faites sur 77 malades obèses, voici notre opinion sur les facteurs de base dans le traitement des obèses: (1) La certitude que les voies respiratoires sont libres, en pratiquant l'intubation chez le malade éveillé si nécessaire. (2) L'usage de pressions intrathoraciques minimales permettant une ventilation efficace ou une ventilation spontanée adéquate. (3) Placer le malade de la façon la plus favorable à la ventilation et à la chirurgie. (4) Placer des moniteurs pour obtenir des renseignements sur tous les paramètres que la situation exige. (5) Avoir la certitude de pouvoir donner des médicaments et des liquides à la vitesse nécessaire dans un cas semblable.

Au cours de la période post-opératoire, il faut obtenir le plus de renseignements possibles sur l'état du malade s'il devient nécessaire de donner un médicament au malade.

\section{REFERENCES}

1. McCracken, Brian H. Etiological Aspects of Obesity. Am. J. Med. Sc. 243: 99 (1962).

2. Hypotonia and Obesity Syndrome. Brit. M. J. 3: 694 (1967).

3. Drugs for Obesity. Brit. M. J. 1: 853 (1963).

4. Wrson, D. R. Drugs for Obesity. Canad. M. A. J. 91 : 1369 (1964).

5. Symposium on Obesity. Brit. M. J. 1: 1149 (1963).

6. Miller, W. F. \& Bashour, F. A. Cardiopulmonary Changes in Obesity. Clin. Anesth. 3: 127 (1963).

7. Sharp, J. T.; Henry, J. P.; Sweany, S. K.; \& Meadows, W. R. The Total Work of Breathing in Normal and Obese Man. J. Clin. Invest. 43: 728 (1964).

8. Alexander, J. K.; Dennis, E. W.; Smith, W. G.; Amad, K. H.; Duncan, W. C.; \& Austis, R. C. Blood Volume, Cardiac Output and Distribution of Systemic Blood Flow in Extreme Obesity. Cardiov. Res. Cent. Bull. 1: 39 (1962).

9. Amad, K. H.; Brennan, J. C.; \& Alexander, J. K. The Cardiac Pathology of Chronic Exogenous Obesity. Circulation. 32: 740 (1965).

10. Rozental, P.; Buava, Claude; Spencer, H.; \& Rimmerman, H. J. Liver Morphology and Function Tests in Obesity and during Total Starvation. Am. J. Dig. Dis. 12: 198 (1967). 
11. Bondar, G. F. Complications of Small Intestine Short Circuiting for Obesity. Arch. Surg. 94: 707 (1967).

12. KING, G. E. Errors in Clinical Measurement of Blood Pressure in Obesity. Clin. Sc. 32: 223 (1967).

13. Seltzer, Carl C. Some reevaluations of the Build and Blood Pressure Study 1959 as Related to Ponderal Index-Somatotype and Mortality. New England J. Med. 274: 254 (1966).

14. Documenta Geigy Scientific Tables, p. 623 (1962).

15. Wyant, Gordon M.; Chang, Chung A.; \& Rapicavoli, Emanuele. Methoxyflurane (Penthrane): A Laboratory and Clinical Study. Canad. Anaesth. Soc. J. 8: 477 (1961).

16. Schwartz, H. Problems of Obesity in Anaesthesia. New York J. Med. 55: 3277 (1955).

17. Noble, Alan B. The Problem of Obesity in Anaesthesia for Abdominal Surgery. Canad. Anaesth. Soc. J. 9: 6 (1962).

18. Gould, Alan B., Jr. Effects of Obesity on Respiratory Complications Following General Anesthesia. Anesth. \& Analg. 41: 448 (1962).

19. Catenacci, A. J.; Anderson, J. D.; \& Boersma, D. Anesthetic Hazards of Obesity. J.A.M.A. 175: 657 (1961).

20. Werner, Helene G. Obesity: A Serious Problem in Anaesthetic Management. J.A.M.W.A. 19: 755 (1964).

21. Greene, B. A. Discussion. New York J. M. 55: 3281 (1955).

22. Jacobs, Leo L.; Bergern, Howard C.; \& Fierro, Frank E. Obesity and Continuous Spinal Anesthesia. Anesth. \& Analg. 42: 547 (1963).

23. Bromage, Philip R. Physiology and Pharmacology of Epidural Anesthesia. Anesthesiology. 28: 592 (1967). 